\title{
ACESSIBILIDADE E A INFRAESTRUTURA PARA INSTITUIÇÕES DE LONGA PERMANÊNCIA PARA IDOSOS
}

\author{
BRUNING, Luise(1); \\ PFUTZENREUTER, Andréa H. (2) \\ (1) Universidade Federal de Santa Catarina, Graduação em engenharia de infraestrutura \\ e-mail:luisebruning@gmail.com \\ (2) Universidade Federal de Santa Catarina, Doutora em Arquitetura e Urbanismo \\ e-mail:andrea.hp@ufsc.br
}

\begin{abstract}
RESUMO
Em 2009 na cidade de Joinville foi consolidado o Conselho Municipal dos Direitos do Idoso (COMDI), entretanto, ainda não utilizam um instrumento homologado para fiscalizar e certificar as Instituições de Longa Permanência para Idosos quanto a sua infraestrutura. O objetivo deste artigo é apresentar uma metodologia para avaliar a acessibilidade e infraestrutura construtiva das ILPIs, baseada nas especificações da RDC № 283 /2005; Portaria oㅜ 73/2001 e do Código de Obras/1964. A validação do instrumento gerou o diagnóstico e a proposição de adequações. Esta metodologia proverá uma ferramenta aos Conselhos Municipais dos Idosos no processo de certificação das ILPIs.
\end{abstract}

Palavras chave: ILPI; acessibilidade e metodologia.

\begin{abstract}
In 2009, the Municipal Council for the Rights of the Elderly was consolidated in the city of Joinville. However, they do not yet use an approved instrument to supervise and certify Elderly Housing regarding their infrastructure. The objective of this article is to present a methodology to evaluate the accessibility and constructive infrastructure of these Housing, based on specifications of RDC $n^{\circ}$ 283/2005; Ordinance $n^{-173 / 2001}$ and of the Code of Construction/1964. The validation of the instrument generated the diagnosis and the proposition of adaptations. The methodology will provide a tool to the Municipal Councils of the Elderly in the process of certification of the construction.
\end{abstract}

Keywords: Elderly housing; acessibility and methodology. 


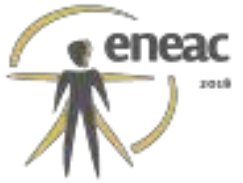

\section{INTRODUÇÃO}

De acordo com o Instituto Brasileiro de Geografia e Estatística (IBGE) no Censo 2010, existem no Brasil cerca de 14 milhões de idosos, sendo que a Região Sul é uma das regiões onde a porcentagem de pessoas com acima de 65 anos é mais elevada, apresentando $8,1 \%$ de idosos. O número de pessoas com mais de 80 anos será cinco vezes maior em 2050 do que era em 2010 (GIAMBIAGI; TAFNER, 2010). Segundo o Centro Internacional de Longevidade Brasil (ILC-Brasil) em 2015, existiam mais de 810 milhões de pessoas acima dos 60 anos no mundo, confirmando o legado da longevidade ao século $\mathrm{XX}$

O relatório mundial sobre envelhecimento e saúde redigido pela Organização Mundial da Saúde (OMS,2015) afirma ser necessário a transformação dos sistemas de saúde para substituir os modelos curativos de ações de atenção integrada e centrada nas necessidades dos idosos, favorecendo o envelhecimento para todos. Para o desenvolvimento de sistemas de cuidados de longo prazo, foram identificadas três abordagens necessárias, que são: (1) Estabelecer as bases necessárias para um sistema de cuidados de longo prazo; (2) Construir e manter uma força de trabalho sustentável e adequadamente treinada; (3) Garantir a qualidade dos cuidados de longo prazo.

No Brasil, segundo Camarano (2010) as políticas de cuidados de longa duração são de responsabilidade do órgão de assistência social, cabendo à vigilância sanitária, através da Agência Nacional de Vigilância Sanitária (ANVISA), o papel de fiscalizar as entidades que cuidam de idosos e de sua permanência. De acordo com a Política Nacional do Idoso (BRASIL, 1994), está prevista a criação e atuação dos Conselhos dos Direitos do Idoso como órgão colegiado e paritário, os quais fiscalizarão as entidades governamentais e nãogovernamentais de assistência ao idoso. Entretanto, mesmo depois de 20 anos, nem todas as cidades estabeleceram esse conselho para atuar com domínio e influência.

Segundo Pfutzenreuter et al. (2009), ainda se encontra dificuldade na adequação das instituições de longa permanência para idosos (ILPI)s à legislação que regula os direitos dos idosos residentes em instituições no Brasil, principalmente ao comparar a Portaria $\mathrm{n}$ 73 de 10 de maio de 2001 (BRASIL, 2001) que define as normas e padrões de funcionamento para serviços e programas de atenção à pessoa idosa e a da RDC n 283 de 26 de setembro de 2005 (BRASIL, 2005), que adota o termo ILPI e estabelece normas de funcionamento dessa modalidade assistencial.

A cidade de Joinville, maior cidade do estado de Santa Catarina, em 2009, consolidou o Conselho Municipal dos Direitos do Idoso (COMDI), vinculado à Secretaria de Assistência Social. Que segundo o item ' $X$ ' do Artigo 3 da Lei $n^{\circ}$ 6588, de 10 de dezembro de 2009 (JOINVILLE, 2009), tem como competência inscrever e fiscalizar entidades 


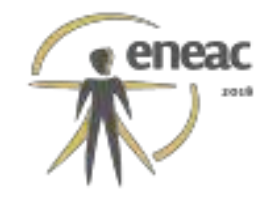

governamentais e não-governamentais de atendimento ao idoso, tais como centros de convivência, casa-lar, oficinas abrigadas de trabalho, centro dia e instituições de longa permanência, fazendo cumprir os preceitos do Estatuto do Idoso, garantindo a regularização e qualidade da infraestrutura e serviços oferecidos aos que nelas vivem.

Em dados fornecidos pelo COMDI de Joinville, no mês de setembro de 2016 foram identificadas 37 Instituições de Longa Permanência para Idosos (ILPIs), totalizando 593 idosos institucionalizados. Dessas instituições, três estão interditadas pela Vigilância Sanitária por motivos não declarados.

Cabe ressaltar que o Conselho ainda não tem um instrumento homologado pelo COMDI municipal e estadual para realizar a fiscalização e certificar as ILPIs quanto a infraestrutura. Em discussões do Conselho e seus relatores, surge a urgência em elaborar um instrumento para avaliar a infraestrutura física construtiva das ILPIs. Sendo importante comparar as legislações vigentes da ANVISA e Governo Federal, regulamentadores da fiscalização para que se realize uma checagem dos elementos de infraestrutura do local.

Como projeto piloto para aplicação do formulário, o COMDI de Joinville indicou à validação do instrumento o Ancianato Bethesda. Esta ILPI foi fundada na década de 1930 com o intuito inicial de servir como lar para idosos, sendo a maior instituição não governamental da cidade de Joinville. Em março de 2017, a instituição era o lar de 91 idosos com diferentes níveis de necessidades.

Desse modo, observando a falta de instrumentos em esferas municipais e estaduais para realizar a fiscalização e a certificação dos Institutos de Longa Permanência para Idoso (ILPIs) quanto a infraestrutura, foi proposta a elaboração de um modelo para avaliar a infraestrutura física construtiva dos mesmos, assim como uma comparação entre as legislações vigentes da ANVISA e Governo Federal, regulamentadores da fiscalização da infraestruturas das ILPIs.

\section{INSTITUIÇÕES DE LONGA PERMANÊNCIA PARA IDOSOS}

Para a ANVISA, as ILPIs são instituições governamentais e não-governamentais, destinadas a domicílio coletivo de pessoas com idade igual ou superior a 60 anos, com ou sem suporte familiar, em condições de liberdade, dignidade e cidadania. O cuidado institucional dos idosos, além dos benefícios de prestação continuada, também faz parte da política assistencial. Assim, o Estado tem papel em promover os serviços para os idosos e fiscalizar as instituições. 


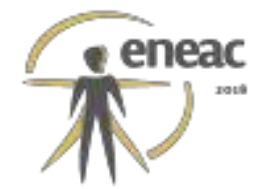

Muitas são as Leis, Portarias e Decretos que fazem alguma referência às ILPIs. Para elucidar a identificação e cronologia, no Quadro 1 apresenta-se o levantamento dos principais documentos existentes e disponíveis à consulta.

\section{Quadro 1 - Normativas relacionadas às ILPIs no âmbito nacional.}

\begin{tabular}{|c|c|c|c|}
\hline Tipo/Número & Data & Abrangência & Disposições \\
\hline Portaria $\mathrm{n}^{\circ} 8.210$ & $\begin{array}{l}22 \text { de setembro } \\
\text { de } 1989\end{array}$ & Brasil & $\begin{array}{l}\text { Aprova normas e padrões para } \\
\text { funcionamento de casas de repouso, } \\
\text { clínicas geriátricas e outras instituições } \\
\text { destinadas as atendimento do idoso. }\end{array}$ \\
\hline Lei ํo 8.842 & $\begin{array}{l}4 \text { de janeiro de } \\
1994\end{array}$ & Brasil & $\begin{array}{l}\text { Dispõe sobre a política nacional do idoso, } \\
\text { cria o Conselho Nacional do Idoso e dá } \\
\text { outras providências. }\end{array}$ \\
\hline Decreto $\mathrm{n}^{0} 1.948$ & $\begin{array}{l}3 \text { de julho de } \\
1996\end{array}$ & Brasil & $\begin{array}{l}\text { Regulamenta a Lei } n^{\circ} 8.842 \text {, de } 4 \text { de } \\
\text { janeiro de } 1994 \text {, que dispõe sobre a } \\
\text { Política Nacional do Idoso, e dá outras } \\
\text { providências. }\end{array}$ \\
\hline Portaria $\mathrm{n}^{0} 1.395$ & $\begin{array}{l}10 \text { de dezembro } \\
\text { de } 1999\end{array}$ & Brasil & Política Nacional de Saúde do Idoso. \\
\hline Portaria no 73 & $\begin{array}{l}10 \text { de maio de } \\
2001\end{array}$ & Brasil & $\begin{array}{l}\text { Oficializa normas de funcionamento de } \\
\text { serviços de atenção ao idoso no } \\
\text { Brasil. }\end{array}$ \\
\hline Lei no 10.741 & $\begin{array}{l}1^{\circ} \text { de outubro de } \\
2003\end{array}$ & Brasil & $\begin{array}{l}\text { Dispõe sobre o Estatuto do Idoso e dá } \\
\text { outras providências. }\end{array}$ \\
\hline $\begin{array}{l}\text { Resolução no } \\
283\end{array}$ & $\begin{array}{l}26 \text { de setembro } \\
\text { de } 2005\end{array}$ & Brasil & $\begin{array}{l}\text { Aprova o Regulamento Técnico que } \\
\text { define normas de funcionamento para } \\
\text { as Instituições de Longa Permanência } \\
\text { para Idosos. }\end{array}$ \\
\hline NBR $9050 / 2015$ & $\begin{array}{l}11 \text { de outubro } \\
\text { de } 2015\end{array}$ & Brasil & $\begin{array}{l}\text { Acessibilidade a edificações, mobiliário, } \\
\text { espaços e equipamentos urbanos }\end{array}$ \\
\hline
\end{tabular}

Fonte: Autores (2016).

$\mathrm{Na}$ portaria $\mathrm{n}^{\circ}$ 73, da Secretaria de Assistência Social do Ministério da Previdência e Assistência Social, ao formular normais para o funcionamento de serviços de atenção ao idoso, introduziu a expressão Atendimento Integral Institucional para designar os programas desenvolvidos em instituições para idosos e definiu três modalidades de atendimento, conforme grau de dependência do idoso:

a) Modalidade l: É a instituição destinada a idosos independentes para atividades da vida diária. Capacidade máxima recomendada de 40 pessoas, com $70 \%$ de quartos para 4 idosos e $30 \%$ para 2 idosos.

b) Modalidade II: É a instituição destinada a idosos dependentes e independentes que necessitam de auxilio e de cuidados especializados e que exijam controle e 


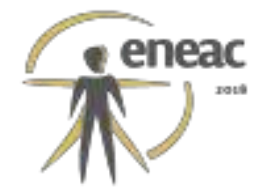

acompanhamento adequado de profissionais de saúde. Capacidade máxima recomendada de 22 pessoas, com $50 \%$ de quartos para 4 idosos e $50 \%$ para 2 idosos.

c) Modalidade III: É a instituição destinada a idosos dependentes que requeiram assistência total, no mínimo, em uma atividade da vida diária. Capacidade máxima recomendada de 20 pessoas, com $70 \%$ de quartos para 2 idosos e $30 \%$ para 4 idosos.

Ainda segundo a Portaria $n^{\circ} 73$, para cada uma dessas modalidades existem metragens mínimas para os diferentes ambientes em uma ILPI, conforme Tabela 1.

Tabela 1 - Programa de necessidades da Portaria no 73 de 2001.

\begin{tabular}{|c|c|c|c|}
\hline \multirow{2}{*}{ Programa de Necessidades } & \multicolumn{3}{|c|}{ Dimensão mínima $\left(m^{2}\right)$} \\
\hline & 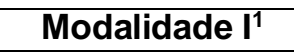 & Modalidade $\|^{2}$ & Modalidade $\mathrm{III}^{3}$ \\
\hline Sala para Direção/Técnicos e Reuniões & 12,00 & 12,00 & 12,00 \\
\hline $\begin{array}{l}2 \text { Salas para Atividades Coletivas ( } 15 \\
\text { pessoas) }\end{array}$ & $2 \times 25,00=50,00$ & $2 \times 25,00=50,00$ & $2 \times 25,00=50,00$ \\
\hline Sala para Atividades Individuais & 8,00 & 8,00 & 8,00 \\
\hline Salas para Atendimento (Multiuso) & & 12,00 & $3 \times 12,00=36,00$ \\
\hline Sala de Convivência & 30,00 & 30,00 & 30,00 \\
\hline Espaço Inter-religioso e para Meditação & - & 20,00 & 20,00 \\
\hline Ambulatório & 8,00 & 8,00 & 8,00 \\
\hline Almoxarifado & 10,00 & 10,00 & 10,00 \\
\hline Copa/cozinha & 16,00 & 16,00 & 16,00 \\
\hline Area de serviço/lavanderia (c/ tanque) & 4,00 & 4,00 & 4,00 \\
\hline Depósito Geral & 4,00 & 4,00 & 4,00 \\
\hline $\begin{array}{l}2 \text { Banheiros para Funcionários (com } \\
\text { armários) }\end{array}$ & $2 \times 3,00=6,00$ & $2 \times 3,00=6,00$ & $2 \times 3,00=6,00$ \\
\hline Dormitórios c/banheiro para 02 pessoas & $6 \times 15,00=90,00$ & $5 \times 15,00=75,00$ & $4 \times 15,00=60,00$ \\
\hline Dormitórios c/banheiro para 04 pessoas & $7 \times 20,00=140,0$ & $3 \times 20,00=60,00$ & $3 \times 20,00=60,00$ \\
\hline Subtotal & 378,00 & 315,00 & 324,00 \\
\hline
\end{tabular}

Fonte: Adaptado da Portaria no 73 (BRASIL, 2001).

\section{Nota:}

${ }^{1}$ Atendimento a 40 idosos e área total construída / usuário $=11,80 \mathrm{~m}^{2}$

${ }^{2}$ Atendimento a 22 idosos e área total construída / usuário $=17,86 \mathrm{~m}^{2}$

${ }^{3}$ Atendimento a 20 idosos e área total construída / usuário $=20,25 \mathrm{~m}^{2}$

${ }^{4}$ no TOTAL não estão incluídas as áreas descobertas destinadas para atividades ao ar livre que deverão ser de, no mínimo, $1,00 \mathrm{~m}^{2}$ por residente

Por sua vez, a RDC n²83 diferencia os graus de dependência que o idoso pode apresentar, sendo eles:

a) Grau de Dependência I - idosos independentes, mesmo que requeiram uso de equipamentos de auto-ajuda;

b) Grau de Dependência II - idosos com dependência em até três atividades de autocuidado para a vida diária tais como: alimentação, mobilidade, higiene, sem comprometimento cognitivo ou com alteração cognitiva controlada; 


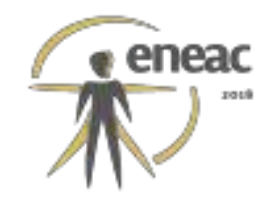

c) Grau de Dependência III - idosos com dependência que requeiram assistência em todas as atividades de autocuidado para a vida diária e ou com comprometimento cognitivo.

Além disso, os municípios brasileiros também fazem uso do Código de Edificações, mais conhecido como Código de Obras, que segundo o Instituto Brasileiro de Administração Municipal (IBAM) é o instrumento que permite à administração municipal exercer o controle e a fiscalização do espaço edificado e seu entorno, garantindo a segurança, salubridade e habitabilidade das edificações (IBAM, 2017). Neste código também estão definidos os procedimentos de aprovação de projeto e licenças de execução de obras, assim como parâmetros para fiscalização do andamento da obra e aplicação de penalidades.

As instituições de longa permanência para idosos, independente da natureza, devem estar regularizadas frente a vigilância sanitária, devendo para tal, antes de iniciar as atividades, protocolar solicitação de parecer sanitário junto a agência de vigilância sanitária a fim de qualificar a prestação de serviços, principalmente quanto à adequação das instalações com relação a RDC № 283 a fim de garantir a população idosa os direitos assegurados na legislação em vigor.

As entidades governamentais e não-governamentais de assistência ao idoso ficam sujeitas à inscrição de seus programas junto ao Conselho Municipal do Idoso, e em sua falta, junto ao Conselho Estadual ou Nacional do Idoso, especificando os regimes de atendimento (Lei no 10.741, 2003).

O Estatuto do Idoso expressa em seu artigo 37 termos como moradia digna e manutenção dos padrões de habitação compatíveis com as necessidades dos idosos. Para assegurar essa dignidade de moradia, a manutenção do ambiente prevê a identificação ao atendimento de sua infraestrutura e o tratamento de patologias construtivas.

\section{METODOLOGIA APLICADA}

Por meio da técnica de Walkthrough, de modo que fosse possível fazer as anotações das metragens e a verificação da existência dos ambientes, percebeu-se que o Ancianato Bethesda possui uma área construída distribuída em setores conforme as ampliações promovidas no decorrer dos anos. Deste modo, a instituição foi separada em alas que correspondem aos diferentes corredores de dormitórios existentes na instituição. As áreas que não estão identificadas são referentes ao uso comum ou de funcionários, como: cozinha, refeitório, ambulatório, espaço ecumênico, entre outros. 


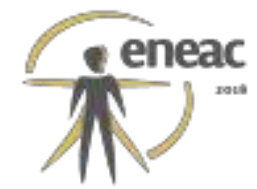

Para elaborar o instrumento (formulário) para análise e avaliação da infraestrutura é necessário primeiro realizar as comparações das especificações das normativas, foi elaborado um quadro com as especificações técnicas presentes na RDC n² 283 de 26 de setembro de 2005 (BRASIL, 2005) e no Código de Obras de Joinville (JOINVILLE, 1964) (ver Quadro 2).

\section{Quadro 2 - Especificações Técnicas da RDC no 283 e do Código de Obras de Joinville} (COJ). (Continua)

\begin{tabular}{|c|c|}
\hline \multicolumn{2}{|r|}{ USO DE FUNCIONÁRIOS } \\
\hline Ambiente & Especificação e Observação \\
\hline $\begin{array}{c}\text { Sala administrativa/reunião } \\
\text { (RDC 283/2005) }\end{array}$ & . Presença obrigatória \\
\hline $\begin{array}{l}\text { Vestiário e banheiro p/ } \\
\text { funcionários, } \\
\text { (RDC 283/2005) }\end{array}$ & $\begin{array}{l}\text { Separado por sexo } \\
\text { Banheiro área mín. } 3,6 \mathrm{~m}^{2} \\
1 \text { chuveiro } \mathrm{p} / \text { cada } 10 \text { funcionários } \\
\text { Área de vestiário mín. } 0,5 \mathrm{~m}^{2} \text { por funcionário/turno }\end{array}$ \\
\hline $\begin{array}{l}\text { Cozinha e despensa } \\
\text { (RDC 283/2005 e COJ) }\end{array}$ & $\begin{array}{l}\text { Não ter comunicação direta com dormitórios e banheiros } \\
\text { Menor dimensão deve ser superior a } 2 \mathrm{~m} \\
\text { Área mín. } 7 \mathrm{~m}^{2} \\
\text { Piso liso, resistente e impermeável } \\
\text {. Paredes impermeabilizadas com material liso até } 1,50 \mathrm{~m} \text { de altura }\end{array}$ \\
\hline $\begin{array}{l}\text { Local para guarda de } \\
\text { material de limpeza } \\
\text { (RDC 283/2005) }\end{array}$ & . Presença obrigatória \\
\hline $\begin{array}{c}\text { Almoxarifado } \\
\text { (RDC 283/2005) }\end{array}$ & . Área mín. $10 \mathrm{~m}^{2}$ \\
\hline \multicolumn{2}{|r|}{ USO COMUM } \\
\hline $\begin{array}{l}\text { Dormitório ( } \mathrm{p} / \text { no máx. } 4 \\
\text { pessoas, com banheiro) } \\
\text { (RDC 283/2005) }\end{array}$ & $\begin{array}{l}\text { Obrigatoriedade na separação por sexo } \\
\text { Dorm. } 01 \text { pessoa, área mín. } 7,50 \mathrm{~m}^{2} \\
\text { Dorm. } 02 \text { a } 04 \text { pessoas, área mínima } 5,50 \mathrm{~m}^{2} \text { por cama } \\
\text { Distância mín. de } 0,80 \mathrm{~m} \text { entre camas e } 0,50 \mathrm{~m} \text { entre cama e parede } \\
\text { lateral } \\
\text { Banheiro área mín. } 3,60 \mathrm{~m}^{2}\end{array}$ \\
\hline $\begin{array}{c}\text { Sala p/ ativ. Coletivas máx. } \\
15 \text { residentes } \\
\text { (RDC } 283 / 2005)\end{array}$ & Área mín. $1 \mathrm{~m}^{2}$ por pessoa \\
\hline $\begin{array}{l}\text { Sala convivência } \\
\text { (RDC 283/2005) }\end{array}$ & . Área mín. $1,3 \mathrm{~m}^{2}$ por pessoa \\
\hline $\begin{array}{l}\text { Sala p/ atividade de apoio } \\
\text { individual e sócio-familiar } \\
\text { (RDC } 283 / 2005 \text { ) }\end{array}$ & . Área mín. 9m² \\
\hline $\begin{array}{l}\text { Espaço ecumênico e/ou } \\
\text { para meditação } \\
\text { (RDC 283/2005) }\end{array}$ & . Presença obrigatória \\
\hline $\begin{array}{c}\text { Refeitório } \\
\text { (RDC 283/2005) }\end{array}$ & Área mín. por usuário $1 \mathrm{~m}^{2}$ \\
\hline $\begin{array}{c}\text { Lavanderia } \\
\text { (RDC 283/2005) }\end{array}$ & . Presença obrigatória \\
\hline
\end{tabular}


Quadro 2 - Especificações Técnicas da RDC no 283 e do Código de Obras de Joinville (COJ). (Conclusão)

\begin{tabular}{|c|c|}
\hline \multicolumn{2}{|r|}{ USO DE FUNCIONÁRIOS } \\
\hline Ambiente & Especificação e Observação \\
\hline $\begin{array}{c}\text { Compartimentos } \\
\text { (COJ) }\end{array}$ & $\begin{array}{l}\text { Permanência prolongada (dormitórios, refeitórios, salas de estar, de } \\
\text { visita, de música, de jogos, de costuras, salas e gabinetes de trabalho, } \\
\text { escritórios, consultórios) } \\
\text { Pé direito mín. } 3 \mathrm{~m} p / \text { até } 2 \text { pav. } \\
\text { Pé direito mín. } 2,80 \mathrm{~m} \mathrm{p} / \mathrm{f}+\text { de } 3 \text { pav. } \\
\text { Piso de área mín. } 8 \mathrm{~m}^{2} \\
\text { Forma em que se possa traçar no piso um círculo de raio de } 1 \mathrm{~m}\end{array}$ \\
\hline & $\begin{array}{l}\text { Permanecia transitória (salas de entrada, salas de espera, corredores, } \\
\text { caixas de escada, rouparias, cozinhas, copas, dispensadas, } \\
\text { banheiros, depósitos) } \\
\text {.Pé direito mín. } 2,60 \mathrm{~m} \text {, salvo sala de espera, pé direito mín. } 3 \mathrm{~m}\end{array}$ \\
\hline
\end{tabular}

\begin{tabular}{|c|c|}
\hline $\begin{array}{c}\text { Banheiros coletivos } \\
\text { (RDC 283/2005 e COJ) }\end{array}$ & Separados por sexo \\
\hline $\begin{array}{c}\text { Área externa para atividades } \\
\text { ao ar livre } \\
\text { (RDC 283/2005) }\end{array}$ & . Bancos, vegetação, solarium e outros \\
\hline $\begin{array}{c}\text { Local para guarda roupas de } \\
\text { uso coletivo } \\
\text { (RDC 283/2005) }\end{array}$ & . Presença obrigatória \\
\hline $\begin{array}{l}\text { Sanitários ou Mictórios } \\
\text { (COJ) }\end{array}$ & $\begin{array}{l}\text { Pé direito mín. } 2,50 \mathrm{~m} \\
\text { Piso liso, impermeável } \\
\text { Paredes impermeabilizadas com material liso até } 1,50 \mathrm{~m} \text { de altura } \\
\text { Dimensões mín. } 1 \times 0,8 \mathrm{~m}\end{array}$ \\
\hline $\begin{array}{l}\text { Múltiplos sanitários ou } \\
\text { Mictórios } \\
\text { (COJ) }\end{array}$ & $\begin{array}{l}\text { Pé direito mín. } 2,60 \mathrm{~m} \\
\text { Abertura para o exterior com área mín. de um sexto }(1 / 6) \text { da área do } \\
\text { piso } \\
\text { Paredes divisórias internas com afastamento mín. de } 0,50 \mathrm{~m} \text { do forro } \\
\text { Passagem de acesso aos sanitários ou mictórios com largura mín.0,80m } \\
\text {. Dimensões mín. } 1 \times 0,8 \mathrm{~m}\end{array}$ \\
\hline $\begin{array}{l}\text { Banheiro } \\
\text { (COJ) }\end{array}$ & $\begin{array}{l}\text { Pé direito mín. } 2,60 \mathrm{~m} \\
\text { Piso liso, impermeável } \\
\text { Paredes impermeabilizadas com material liso até } 1,50 \mathrm{~m} \text { de altura } \\
\text {. Sanitário de uso exclusivo de } 1 \text { ou } 2 \text { dormitórios não precisa ter abertura } \\
\text { direta para o exterior, desde que tenha sua ventilação por meio de } \\
\text { comunicação com o exterior, estabelecida por essa que deverá satisfazer } \\
\text { as seguintes condições: } \\
\text { a) altura mín. } 0,20 \mathrm{~m} \\
\text { b) secção mín. } 0,12 \mathrm{~m}^{2} \\
\text { c) extensão máx. } 5 \mathrm{~m}\end{array}$ \\
\hline
\end{tabular}

Fonte: Adaptado pelo autor de COJ (1964) e RDC ํㅡ 283 (2005).

Após a compilação das especificações técnicas das normativas percebe-se que alguns itens não condizem com o que é consolidado pelo Código de Obras do município em projetos de edificações. Sendo necessário adequar o formulário para posterior aplicação. 
(COJ).

\begin{tabular}{|c|c|}
\hline \multicolumn{2}{|r|}{ DEMAIS ITENS } \\
\hline Ambiente & Especificação e Observação \\
\hline $\begin{array}{l}\text { Acesso externo } \\
\text { (RDC 283/2005) }\end{array}$ & $\begin{array}{l}\text { Mínimo } 2 \text { portas } \\
.1 \text { exclusiva p/ serviço }\end{array}$ \\
\hline $\begin{array}{c}\text { Pisos (inter. e ext.) } \\
\text { (RDC 283/2005)20065 }\end{array}$ & . Antiderrapantes \\
\hline $\begin{array}{c}\text { Rampas } \\
\text { (RDC 283/2005) }\end{array}$ & $\begin{array}{l}\text { 1,20m de largura } \\
\text { Seguir NBR9050 } \\
\text { Rampas de acesso, inclinação máx. 5\%, largura mín. } \\
1,50 \mathrm{~m} \text {, guarda-corpo e corrimão (MOSSC) }\end{array}$ \\
\hline $\begin{array}{c}\text { Escadas } \\
\text { (RDC 283/2005 e COJ) }\end{array}$ & $\begin{array}{l}\text { Largura livre mín. } 1,20 \mathrm{~m} \\
\text { Altura livre mín. } 2 \mathrm{~m} \\
\text { Degraus de no máx. } 0,19 \text { (altura) } \times 0,25 \mathrm{~m} \text { (largura) } \\
\text {. Patamar de no mín. 0,80m quando exceder } 19 \text { degraus } \\
\text { consecutivos } \\
\text {. Seguir NBR9050 }\end{array}$ \\
\hline $\begin{array}{l}\text { Circulação interna } \\
\text { (RDC 283/2005) }\end{array}$ & $\begin{array}{l}\text { Principal }-1 \mathrm{~m} \text { largura } \\
. \text { Secundária }-0,80 \mathrm{~m} \text { largura } \\
. \geq 1,50 \mathrm{~m} \text { corrimão ambos os lados } \\
. \leq 1,50 \mathrm{~m} \text { corrimão em apenas um dos lados }\end{array}$ \\
\hline $\begin{array}{c}\text { Portas } \\
\text { (RDC 283/2005) }\end{array}$ & Vão livre mínimo $1,10 \mathrm{~m}$ \\
\hline $\begin{array}{l}\text { Janelas e guarda-corpos } \\
\text { (RDC 283/2005) }\end{array}$ & Peitoris mínimo de $1 \mathrm{~m}$ \\
\hline $\begin{array}{l}\text { Corredores } \\
(\text { COJ })\end{array}$ & $\begin{array}{l}\text { Pé direito mín. } 2,40 \mathrm{~m} \\
\text { Até } 5 \mathrm{~m} \text { de comprimento, largura mín. } 1,20 \mathrm{~m} \\
\text {. Maior que } 5 \mathrm{~m} \text { de comprimento, largura mín. 1,50m e } \\
\text { ventilação }\end{array}$ \\
\hline $\begin{array}{c}\text { Cobertura } \\
(\text { COJ })\end{array}$ & Material impermeável, de reduzida condutibilidade térmica \\
\hline $\begin{array}{l}\text { Lixeira externa } \\
\text { (RDC 283/2005) }\end{array}$ & . Presença obrigatória \\
\hline $\begin{array}{l}\text { Iluminação e ventilação } \\
\text { (COJ) }\end{array}$ & $\begin{array}{l}\text { Superfície das aberturas para o exterior em cada } \\
\text { compartimento } \\
. \geq 1 / 5 \text { da superfície do piso nos dormitórios } \\
. \geq 1 / 6 \text { da superfície do piso nas salas de estar, refeitórios, } \\
\text { escritórios, cozinhas, copas e banheiros } \\
\text {. Abertura mín. } 0,3 m^{2} \\
\text {. Escadas com iluminação em cada pavimento por janelas } \\
\text { ou vitrais }\end{array}$ \\
\hline
\end{tabular}

Fonte: Adaptado pelo autor de COJ (1964) e RDC № 283 (2005).

Com as especificações do Quadro 2 e da Tabela 1, foi possível elaborar o formulário inicial, utilizando uma ILPI para o seu pré teste de avaliação de aplicabilidade e posterior melhoria do instrumento, os resultados serão recursos importantes para a validação da legibilidade dos conteúdos e informações. 


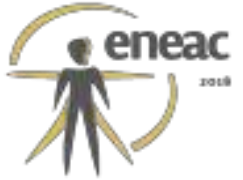

\section{RESULTADOS E DISCUSSÕES}

Os dados obtidos com a aplicação do formulário apresentaram que os vestiários e os banheiros de funcionários não estão adequados às normativas. Ao realizar o levantamento foi encontrado uma área de $3,19 \mathrm{~m}^{2}$ e $3,04 \mathrm{~m}^{2}$ nos banheiros feminino e masculino, respectivamente; a presença de um chuveiro apenas no banheiro feminino e a área de vestiário era de $2,61 \mathrm{~m}^{2}$ e $2,39 \mathrm{~m}^{2}$.

Como o turno de maior representatividade de funcionários é o da manhã, com 54 pessoas, este foi o utilizado para a base dos cálculos das dimensões mínimas que deveria ser de $27 \mathrm{~m}^{2}$, se considerarmos metade dos funcionários do sexo masculino e metade do sexo feminino são necessários $13,5 \mathrm{~m}^{2}$ para cada um dos vestiários, valor muito superior aos $2,61 \mathrm{~m}^{2}$ e $2,39 \mathrm{~m}^{2}$ encontrados na ILPI.

Ainda, considerando o número de 54 funcionários, deveriam existir mais de 5 chuveiros na instituição e não apenas 1 como o constatado. A solução para essas desconformidades é a ampliação do vestiário existente ou a construção de novos vestiários, que atendam inclusive a questão da acessibilidade.

Outros itens não conformes são o peitoril das janelas que está $10 \mathrm{~cm}$ menor do que o normatizado. Por serem janelas de acesso restrito e que normalmente estão fechadas, a simples inclusão de uma obstrução de segurança aos $10 \mathrm{~cm}$ já seria o suficiente. $O$ que poderia ser construído em madeira ou material polimérico. Um item mais preocupante é o piso externo cerâmico com características não antiderrapantes sendo necessária a aplicação de produto sobre o piso existente para deixa-lo antiderrapante, ou a troca de piso, assegurando o cuidado aos idosos e evitando quedas e possíveis fraturas.

O item que mais se distancia das normativas é o que diz respeito a área mínima dos banheiros. Dentre os sete banheiros diagnosticados, seis apresentaram uma área de aproximadamente $0,5 \mathrm{~m}^{2}$ menor do que o especificado em norma. A adequação dos banheiros da ILPI às normativas pode ser realizada com a demolição e reconstrução da parede, aumentando em $30 \mathrm{~cm}$ a largura do ambiente. Esses $30 \mathrm{~cm}$ garantem o ganho dos $0,5 \mathrm{~m}^{2}$ necessários para a conformidade com as normas. Além do que o espaço da edificação permite que isto seja realizado. Entretanto, para que esse serviço fosse realizado em todos os banheiros desconformes, os idosos teriam que ser realocados de seus dormitórios evitando constrangimentos, problemas salutares com os ruídos e poeira proveniente das obras. 


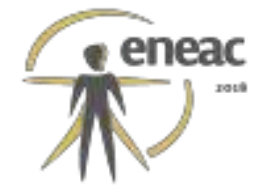

Cabe ressaltar que apesar da não adequação dos banheiros ao Código de Obras de 1964 do município, as dimensões atendem a NBR 9050 de 11 de setembro de 2015 (ABNT, 2015), que estabelece as dimensões mínimas para manobra de cadeiras de rodas sem deslocamentos de $90^{\circ}$ sendo de $1,20 \mathrm{~m} \times 1,20 \mathrm{~m}$. O que gera uma inquietação quanto a necessidade de revisão e atualização do Código de Obras da Cidade, passados mais de 50 anos desde a data de sua aprovação.

Dentre todas as manifestações patológicas registradas, algumas apresentam caráter de importância, pois podem afetar diretamente a saúde de quem convive com elas. Como são os casos observados do mofo e bolor nas paredes internas do ambiente, do descolamento de pisos vinílicos e as fissuras na estrutura interna que afetam diretamente o piso do corredor.

\section{CONSIDERAÇÕES FINAIS}

O envelhecimento da população de forma crescente e perceptível faz com que um olhar mais crítico seja percebido sobre a situação dos idosos. As instituições de longa permanência apresentam uma importância social para um número cada vez maior de pessoas, justificando a relevância do estudo dessas instituições de convívio e morar.

Com a aplicação de um instrumento que avalie a infraestrutura, os orgãos ficalizadores terão uma ferramenta de especificações das normativas vigentes no que diz respeito à adequações e construções das ILPIs. Deste modo, a certificação gerada pelos Conselhos dos Idosos às instituições poderão ser realizadas considerando quesitos de qualificação dos ambientes.

Por esse motivo, o instrumento de avaliação revela sua importância como papel social para atestar que os idosos institucionalizados tenham a sua disposição pelo menos o mínimo de infraestrutura que já está prevista por lei. Satisfazendo as premissas do Estatuto do Idoso quanto a moradia digna e manutenção dos padrões de habitação compatíveis com as necessidades dos idosos.

\section{REFERÊNCIAS BIBLIOGRÁFICAS}

BRASIL. Ministério da Saúde. RDC no 283, de 26 de setembro de 2005.Aprova o Regulamento Técnico que define normas de funcionamento para as Instituições de Longa Permanência para Idosos. Brasília: Diário Oficial da União, 27 set. 2005. Disponível em: <http://sbgg.org.br/wpcontent/uploads/2014/10/rdc-283-2005.pdf>. Acesso em: 30 out. 2016.

Ministério da Saúde. Portaria no 1.395, de 10 de dezembro de 1999.Política Nacional de Saúde do Idoso. Brasília: Diário Oficial da União, 13 dez. 1999. Disponível em:

$<$ http://www.saudeidoso.icict.fiocruz.br/pdf/PoliticaNacionaldeSaude

daPessoaldosa.pdf>. Acesso em: 24 set. 2016. 


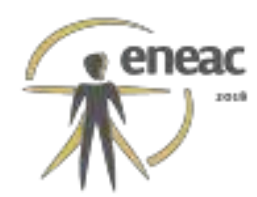

Presidência da República. Lei no 8.842, de 4 de janeiro de 1994. Dispõe sobre a política nacional do idoso, cria o Conselho Nacional do Idoso e dá outras providências. Brasília, DF. Disponível <http://www.planalto.gov.br/ccivil_03/leis/L8842.htm>. Acesso em: 24 set. 2016.

em:

Presidência da República. Lei no $\mathbf{1 0 . 7 4 1}$, de 1ํ de outubro de 2003. Dispõe sobre o Estatuto do Idoso e dá outras providências. Brasília, DF. Disponível em:

< http://www.planalto.gov.br/ccivil_03/leis/2003/L10.741.htm>. Acesso em: 16 abr. 2017.

Secretaria de Assistência Social do Ministério da Previdência e Assistência Social. Portaria no 73, de 10 de maio de 2001. Oficializa normas de funcionamento de serviços de atenção ao idoso no Brasil. Disponível em: <http://sisapidoso.icict.fiocruz.br/>. Acesso em: 30 out. 2016.

CAMARANO, A. A.; KANSO, S. As instituições de longa permanência para idosos no Brasil. In: XVII ENCONTRO NACIONAL DE ESTUDOS POPULACIONAIS, 2010, Rio de Janeiro: [s.n.], 2010. Disponível em: <http://www.abep.nepo.unicamp.br/encontro2010/docs_pdf/tema_7/abep2010_2515.pdf>. Acesso em: 02 set. 2016.

GIAMBIAGE, F.; TAFNER, P. Demografia: a ameaça invisível: o dilema previdenciário que o Brasil se recusa a encarar. Rio de Janeiro: Elsevier, 2010.

IANTAS, L. C. Estudo de caso: análise de patologias estruturais em edificação de gestão pública. 2010. 58 p. Tese (Pós-Graduação) - Programa Residência Técnica da Secretaria de Estado de Obras Públicas/SEOP. Pós Graduação em Construção de Obras Públicas da Universidade Federal do Paraná, Curitiba. 2010.

INSTITUTO BRASILEIRO DE GEOGRAFIA E ESTATÍSTICA. Censo 2010. Disponível em:<http://censo2010.ibge.gov.br/>. Acesso em: 27 ago. 2016.

JOINVILLE. Lei no 667, de 8 de maio de 1964. Sanciona o Código de Obras da cidade de Joinville. Disponível em: <https://leismunicipais.com.br/codigo-de-obras-joinville-sc>. Acesso em: 24 set. 2016.

Lei no 6588, de 10 de dezembro de 2009. Cria o Conselho Municipal dos Direitos do Idoso: COMDI e o Fundo Municipal dos Direitos do Idoso - FMDI. Joinville, SC. Disponível em: <https://www.joinville.sc.gov.br/departamento/comdi/>. Acesso em: 27 ago. 2016.

ORGANIZAÇÃO MUNDIAL DA SAÚDE. Relatório mundial de envelhecimento e saúde, 2015 Disponível em: <http://sbgg.org.br/wp-content/uploads/2015/10/OMS-ENVELHECIMENTO-2015port.pdf>. Acesso em: 02 set. 2016.. 